http://jmscr.igmpublication.org/home/

ISSN (e)-2347-176x ISSN (p) 2455-0450

crossref DOI: https://dx.doi.org/10.18535/jmscr/v7i10.81

Journal Of Medical Science And Clinical Research

\title{
Lofgren Syndrome: Acute Variant of Sarcoidosis- A Case Report
}

\author{
Authors \\ Dr Srikant Sharma ${ }^{1}$, Dr Pawan Mangla ${ }^{2}$, Dr Nisarg Patel ${ }^{3}$ \\ ${ }^{1}$ Senior Consultant Department of Internal Medicine, Moolchand Medcity, New Delhi \\ ${ }^{2}$ Senior Consultant Chest Physician, Moolchand Medcity, New Delhi \\ ${ }^{3}$ Resident, Medicine, Moolchand Medcity, New Delhi
}

\begin{abstract}
Lofgren's syndrome is an acute form of sarcoidosis, characterized by the triad of polyarthritis, hilar adenopathy and erythema nodosum. Here, we report a case who presented with polyarthralgia and rash. Skin biopsy from rash revealed erythema nodosum. Chest imaging showed enlarged multiple mediastinal lymph nodes.
\end{abstract}

\section{Introduction}

Lofgren syndrome is seen in less than $5 \%$ to $10 \%$ of sarcoidosis cases and is usually self-limiting. Joint involvement in Lofgren syndrome is the most common presentation of acute sarcoid arthritis. It most commonly presents as arthritis/periarthritis involving both ankles. In more than $90 \%$ of cases, the acute polyarthritis involves both ankles. Approximately $15 \%$ of patients with Lofgren syndrome have an elevated Angiotensin converting enzyme (ACE) level. Those with an elevated ACE level tend to have a more persistent arthritis. The presence of all of the features of Lofgren syndrome has a $95 \%$ diagnostic specificity for sarcoidosis, allowing a clinical diagnosis to be made without biopsy.

According to the Visser criteria for sarcoidosis in patients with arthritis and bilateral hilar lymphadenopathy, patients must have the 3 of the following 4 characteristics in order to establish the diagnosis (sensitivity, 93\%; specificity, 99\%):

- Age less than 40 years

- Erythema nodosum

- Symptom duration less than 2 months
- Symmetric ankle arthritis

In addition to the Visser criteria, symptoms of sarcoid arthritis vary among patients. Most white patients presenting with Lofgren syndrome have spontaneous remission. Symptomatic treatment of acute sarcoid arthropathy includes the use of NSAIDs.

\section{Case Report}

63 year old Female came with h/o 1 week fever followed by 2 months h/o bilateral ankle swelling, pain and tenderness up to restricting activities, with painful purplish nodules over shins and forearm, with past h/o uveitis, with high ESR.

History of Present illness

- She was asymptomatic two months back when she noticed pain and swelling in both ankles, progressive. Walking was painful and it restricted her activities.

- She also noticed painful purplish nodules on forearm and shin. She was treated by doctors with NSAIDs. There was no relief. 


\section{Past History}

- Known asthmatic for many years.

- Known hypertensive, well-controlled with tablet LISTRIL $2.5 \mathrm{mg}$ daily.

- No history of anti TB treatment.

- She was also found to have circumcorneal injection suggestive of uveitis.

- She was diagnosed with glaucoma by eye surgeon.

\section{Personal History}

- She retired as a Senior teacher from a Public School, non-smoker, non-alcoholic.

\section{Examinations}

- 63-year-old pleasant female, obese, conscious and well-oriented to surroundings in time and space.

- Pulse- 80/min, BP 140/80 mm Hg, Respiratory rate $16 / \mathrm{min}$, Afebrile, No peripheral lymphadenopathy.

- There was swelling of both ankles, with tenderness and pitting edema.

\section{On Systemic Examinations}

- Chest, Cardiovascular, Per-abdomen, and Central nervous system - Normal

\section{Investigations}

- $\mathrm{Hb} 9.7$ g\%, TLC 9.6/cmm, P75, L20, E3, $\mathrm{M} 2$.

- ESR $110 \mathrm{~mm}^{\mathrm{st}} \mathrm{hr}$.

- Urine Normal.

- Random Blood glucose 106 mg\%.

- $\quad$ APTT $35 \mathrm{sec}$ (Test), $34 \mathrm{sec}$ (Control)

- PT $17 \mathrm{sec}$ (Test), $14 \mathrm{sec}$ (Control)

- $\quad$ INR 1.3

Fig 1. CXR showing Hilar Lymphadenopathy

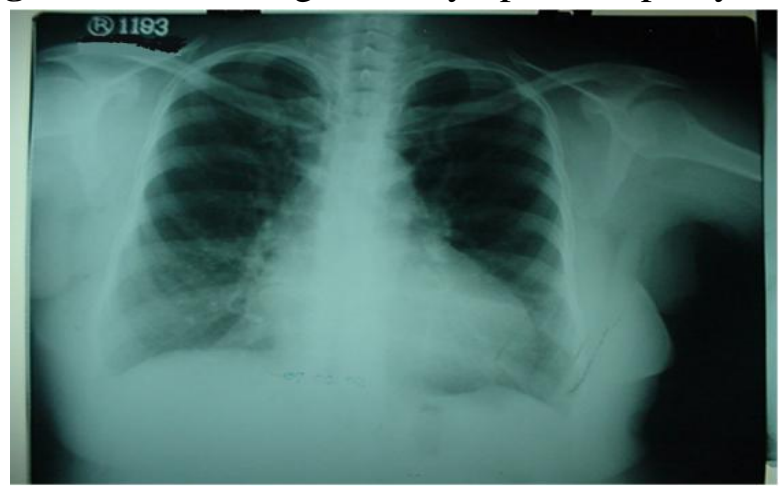

Fig 2 CT chest confirming hilar lymphadenopathy

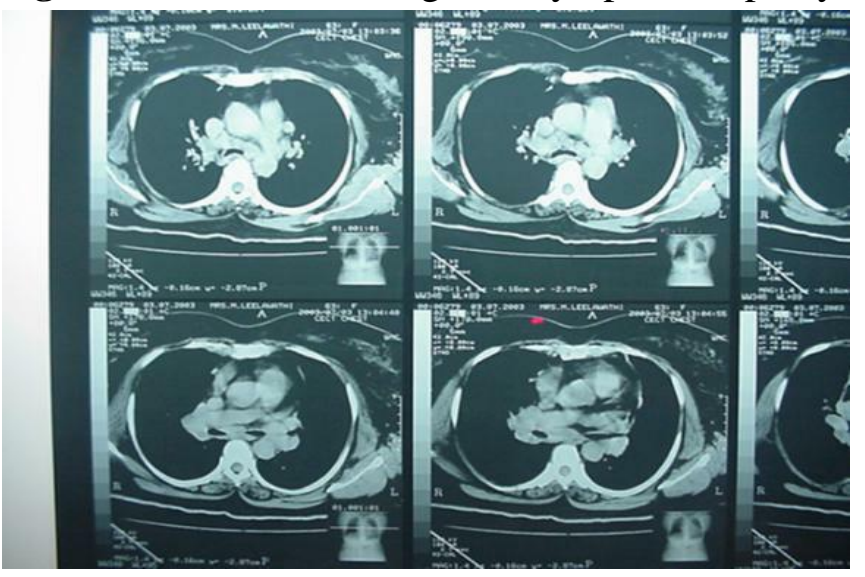

Fig 3 X-ray ankle showing arthritic changes
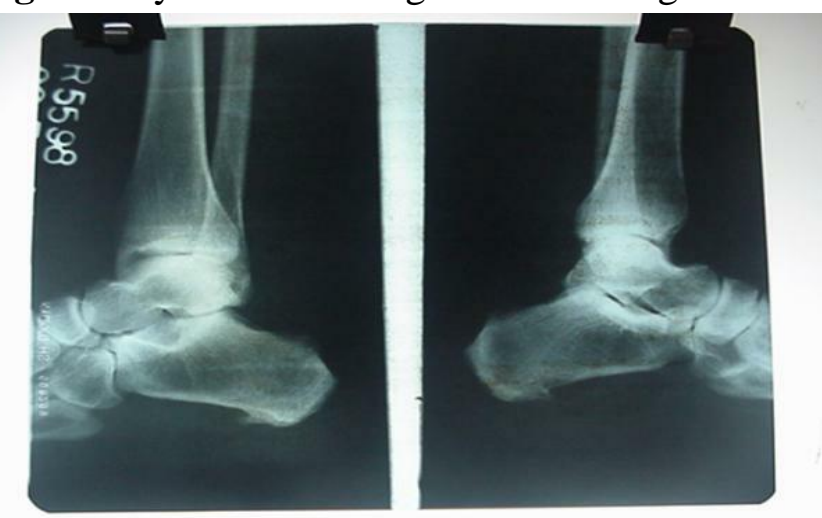

\section{Diagnosis}

- LOFGREN'S SYNDROME was made and METHOTREXATE and MEDROL was started.

- Patient became asymptomatic in a week time and started walking without pain.

- She became asymptomatic.

\section{Treatment}

1) Initiate METHOTREXATE $0.6 \mathrm{ml}$ (15 mg) I.M. weekly x 2 weeks, then increased the dose to $0.8 \mathrm{ml}(20 \mathrm{mg})$ weekly I.M.

2) MEDROL $4 \mathrm{mg}$ tablets - 3 tablets, 30minutes before inj METHOTREXATE. On the other 6 days of the weeks, $1 / 2$ tab MEDROL twice a day.

3) FOLVITE $5 \mathrm{mg}$ tab daily except on the day of Inj METHOTREXATE.

4) HCQS $200 \mathrm{mg} 2$ tab daily after dinner. 


\section{Discussion}

In 1953, Sven Lofgren first described Lofgren's syndrome. He studied 212 adult patients bilateral hilar lymphadenopathy. They were practically regarded as sarcoidosis since they did not have active evidence of tuberculosis. Lofgren demonstrated that erythema nodosum was present at the onset of disease in 113 cases in which articular symptoms (either pain in the joints or/with swelling) were common.

Lofgren's syndrome is a rare variant of sarcoidosis. The presence of all the three features of the Löfgren syndrome (bilateral ankle arthritis, hilar lymphadenopathy and erythema nodosum) has a 95 percent diagnostic specificity for sarcoidosis. Hence diagnosis can be made without biopsy. Other differentials of Lofgren's syndrome include fungal infection, tuberculosis, lymphomas, and bronchogenic carcinoma. Angiotensin converting enzyme (ACE) level is elevated in only $50 \%$ of patients presenting with erythema nodosum, having sarcoidosis. ACE level again is non-specific and can be elevated in hepatitis, or lymphomas $^{[1]}$. This syndrome is related to HLAB8 and DR3 in Caucasians ${ }^{[2]}$. Hence having some relationships with genetic predisposition. The siltzbach staging system for sarcoidosis based on chest radiographic findings, has its prognostic value. Though chest radiograph is widely used for diagnosis, CT (computer tomography) is superior in delineating nodal stations and lung parenchymal changes. In sarcoidosis, CT implies bilateral symmetric hilar and right paratracheal lymph node enlargement (referred to as Garlands triad, or 1-2-3 sign or pawn breakers sign). In sarcoidosis, left paratracheal and aorto-pulmonary nodes are also frequently enlarged, and which can be seen in CT scan. Bilateral hilar node enlargement alone or in combination with mediastinal node enlargement occurs in $95 \%$ of cases of sarcoidosis ${ }^{[3]}$. Though the differentials include infection (tuberculosis or fungal) and malignancy (lymphoma), sarcoidosis is the most common cause of bilateral hilar lymph node enlargement. Mediastinal adenopathy without hilar involvement is more suggestive of lymphoma. Also Internal mammary and retrocrural lymphadenopathy implies lymphoma. Also lymph nodes in lymphoma show pressure effect on adjacent structures, unlike sarcoid. Our case can be categorized as stage 1, Siltzbach classification based on the presence of bilateral hilar with mediastinal adenopathy, without pulmonary infiltrates. Hence Prognosis in such cases is extremely good. NSAIDs, bed rest and Steroids can be used in serious arthritis, hypercalcemia, and granulomatous skin lesions ${ }^{[4]}$.

\section{Conclusion}

Lofgren's syndrome is an acute variant of sarcoidosis and can present as fever with generalized rash and arthralgia. It is often difficult to differentiate Lofgren's syndrome from viral exanthematous fever, where joint pain may recover within 6 weeks. Patients with bilateral hilar lymphadenopathy without pressure effects suggest sarcoidosis. Lofgren's syndrome has a very good prognosis. Treatment with nonsteroidal anti-inflammatory agents (NSAIDs) is usually adequate to control symptoms, but occasional patients will need additional therapy.

\section{References}

1. Mana J, Gomez-Vaquero C, Salazar A, Valverde J, Juanola X, Pujol R. Periarticular ankle sarcoidosis: a variant of Lofgren's syndrome. J Rheumatol. 1997; 24(1):239.

2. Bogunia-Kubik K, Tomeczko J, Suchnicki K, Lange A. HLA-DRB1 03, DRB1 11 or DRB1 12 and their respective DRB3 specificities in clinical variants of sarcoidosis. Tissue Antigens 57: 87-90, 2001.

3. Criado E, Sanchez M, Ramiŕ ez J, Arguis P, de Caralt TM, Perea RJ, Xaubet A. Pulmonary sarcoidosis: typical and atypical manifestations at high-resolution CT with pathologic correlation. 
Radiographics. 2010 Oct; 30(6):1567-Med

Case Rep: Volume 3 (2017)

4. Ohta H, Tazawa R, Nakamura A, et al. Acute-onset sarcoidosis with erythema nodosum and polyarthralgia (Lofgren's syndrome) in Japan: a case report and a review of the literature. Intern Med. 2006; 45(9):659-662. 